\title{
Reduced Electroencephalographic Coherence Asymmetry in the Chernobyl Accident Survivors
}

\author{
Ludmila A. Zhavoronkova1, Nina B. Kholodova², Alexey P. Belostocky ${ }^{1}$, and Mikhail A. Koulikov ${ }^{1}$ \\ ${ }^{1}$ Institute of Higher Nervous Activity and Neurophysiology, Russian Academy of Sciences (Russia) \\ ${ }^{2}$ Rentgenoradiological Centre, Ministry of Health of the Russian Federation (Russia)
}

\begin{abstract}
An electroencephalograph (EEG) study was carried out from 1990 to 2006, using power spectra, averaged coherence, and integral EEG coherence asymmetry coefficients to compare 189 clean-up workers of the Chernobyl accident with 63 age-matched healthy controls. Most of the Chernobyl workers showed three abnormal EEG patterns, as indicated by EEG power mapping. The higher power, most prominent in slow alpha and theta bands, or in fast alpha frequencies, were observed in persons 3-5 years after the clean-up works (the early stage). The lower EEG power in alpha band was found in Chernobyl workers 10 or more years after the accident (the late stage). EEG coherence analysis revealed the existence of two stages in EEG alterations following the Chernobyl clean-up. In the early stage, an increase of EEG coherence in the central brain areas was observed, whereas at the later stage, a decrease of EEG coherence, most prominent in the frontal brain areas, and reduced brain asymmetry prevailed. These results allow us to propose that the described EEG signs may be a reflection of radiation-induced brain dysfunction at the late period after the Chernobyl clean-up and were similar to the EEG markers of brain ageing. The results, in comparison to data of the literature, provide additional support to the premature brain ageing hypothesis in Chernobyl survivors as a result of the radiation brain damage after-effect. Keywords: EEG power and coherence, interhemispheric asymmetry, Chernobyl accident, radiation, brain ageing
\end{abstract}

\begin{abstract}
Se llevó a cabo un estudio electroencefalográfico (EEG) desde 1990 a 2006, empleando los espectros de energía, la coherencia promediada y los coeficientes integrales de asimetría de coherencia de EEG para comparar 189 trabajadores que participaron en la limpieza después del accidente de Chernobyl con un grupo control de 63 individuos sanos de la misma edad. La mayoría de los trabajadores de Chernobyl mostraron tres patrones anormales de EEG, como indica el mapeo de energía del EEG. La energía más alta, más prominente en las bandas lentas alfa y theta (1) o en frecuencias rápidas alfa (2), se observó en personas estudiadas 3 a 5 años después de los trabajos de limpieza (la fase temprana). La energía en el EEG más baja, en la banda alfa (3), se encontró en los trabajadores de Chernobyl 10 años o más después del accidente (la fase tardía). El análisis de coherencia del EEG reveló la existencia de dos fases en las alteraciones del EEG después de la limpieza de Chernobyl. En la fase temprana, se observó un incremento de la coherencia del EEG en las áreas centrales del cerebro, mientras que en la fase tardía, se observó una reducción de la coherencia del EEG, más prominente en las áreas frontales del cerebro, y prevaleció la reducción de la asimetría del cerebro. Estos resultados nos permiten proponer que los signos EEG descritos pueden ser un reflejo de disfunción cerebral inducida por radiación en la fase tardía después de la limpieza de Chernobyl y que son similares a los marcadores EEG del envejecimiento del cerebro. Los resultados, en comparación con los datos de la literatura, proporcionan apoyo adicional a la hipótesis del envejecimiento cerebral prematuro del cerebro en los supervivientes de Chernobyl como resultado del efecto secundario de lesiones cerebrales por radiación.

Palabras clave: energía y coherencia de EEG, asimetría inter-hemisférica, accidente de Chernobyl, radiación, envejecimiento cerebral
\end{abstract}

Correspondence concerning this article should be addressed to Ludmila A. Zhavoronkova, Institute of Higher Nervous Act. \& Neurophysiology RAS, Butlerov str. 5a, 117485 Moscow, Russia. Work phone: +7-499- 97-85-59. Fax: +7-495-338-85-00. E-mail: Lzhavor@nsi.ru

How to cite the authors of this article: Zhavoronkova, L.A., Kholodova, N.B. and Belostocky, A. 
Twenty years after the Chernobyl accident, the issue of health disorders, brain malfunctions, and cognitive impairments among the Chernobyl clean-up workers is still a point of much controversy. However, some decades ago, in experimental and clinical studies, it was shown that exposure to ionizing radiation, even low doses, is the most dangerous environmental hazard for humans and can produce multiple after-effects (e.g., Klimendof \& Hant, 1969; Livanov, 1961; Mickley, 1987). Numerous studies revealed that ionizing radiation affects the central nervous system (CNS) functions both directly and indirectly through CNS response to the damage of other systems, for instance, the vascular system of the brain (Davidov, Ushakov, \& Fedorov, 1991; Yaar, Ron, \& Modan, 1982). After the Chernobyl accident, the number of publications concerning the clinical after-effects of ionizing radiation has increased dramatically (Loganovsky \& Yuryev, 2001, 2004; Nyagu, Noschenko, \& Loganovsky, 1999; Zubovsky \& Kholodova, 1993).

During the early period after the Chernobyl accident, much attention focused on acute radiation sickness induced by a high dose of radiation, whereas the consequences of a low dose of radiation with the first indications of disease appeared only 3-4 years after the Chernobyl accident (Meshkov, Rychov, Kuznetsova, Shlyk, Zhavoronkova, \& Kholodova,, 1993; Nyagu et al. 1997, 1999). Multiple disorders, including physical well-being, the immune, cardiovascular, endocrine, and neural systems were found to be typical of the Chernobyl clean-up workers. After the Chernobyl accident, an increase of cases of oncological pathology, including leukemia and thyroid cancer, was described in the Chernobyl clean-up workers and in the general population of the radiated territories (e.g., Gluzman et al., 2006; Loganovsky \& Loganovskaya, 2000; Loganovsky \& Yuryev, 2001, 2004; Mironov, Tretyakevich, \& Zhuravkov, 2006). Previous data from longitudinal investigations of the consequences of the Chernobyl accident show that the clinical and mental disorders of the Chernobyl clean-up workers have gotten worse rather than declining with time (e.g., Loganovsky \& Yuriev, 2001, 2004; Zhavoronkova, Gogitidze, \& Kholodova, 1999).

Taking into account the wide spectrum of functional impairment in Chernobyl clean-up workers, the choice of adequate methods for diagnosis and investigation in the first years after the Chernobyl accident, especially of persons who were not diagnosed with acute radiation sickness, was important and difficult. Complex investigations were carried out by the Ukraine investigators of the Scientific Center for Radiation Medicine and included epidemiological, radiological, clinical, psychopathological, and electrophysiological studies to determine the radiation aftereffect in persons who took part cleaning up Chernobyl in 1986-1987- the "liquidators" (Loganovsky \& Loganovskaya, 2000; Nyagu et al., 1999). An attempt to elucidate the radiation after-effect and to estimate effect of different doses of radiation was performed. In these studies, several groups of individuals were compared: liquidators with acute radiation sickness, liquidators without acute radiation sickness, Afghanistan war veterans with stress disorders and closed head trauma, similar persons without head trauma, and age-matched healthy controls. It was shown that, in the early stage after the Chernobyl accident, health disorders in Chernobyl clean-up workers was conditioned by some factors, including radiation and stressors. Clinical and neurophysiological changes in Chernobyl liquidators radiated with small doses were probably a result of psychogenetic trauma including a stressor factor. In the later stage, the electrophysiological and psychopathological signs of left fronto-temporal (possibly of limbico-reticular complex) dysfunctions were observed in all liquidators and they correlated with the dose of radiation (Loganovasky \& Loganovskaya, 2000).

The electroencephalograph (EEG) power method is widely used as an electrophysiological approach to the experimental study of the basic mechanisms of brain functions, for clinical diagnosis including postradiation pathology. The high sensitivity of the EEG coherence method for reflecting the functional connectivity between different brain areas, with regard to the evaluation of brain activity in healthy subjects, was supported by a number of papers (Boldyreva, 2000; Boldyreva, Zhavoronkova, Sharova, \& Dobronravova, 2007; French \& Beaumont, 1984; Petsche, 1996; Rappelsberger \& Petsche, 1988; Rusinov, Grindel, Bodyreva, \& Vakar, 1987; Tucker, Roth, \& Bait, 1986). The EEG coherence-related parameters were tested in a number of clinical investigations, for example, in neurosurgical patients (Boldyreva, 2000; Boldyreva et al., 2007; Michelogianis, Paritsis, \& Trikas, 1991; Nagase, Okubo, Matsura, Kojima, \& Toru, 1992; Sharova, 1999), patients with developmental psychopathology (Knyazeva \& Innocenti, 2001; Marosi et al., 1992, Thatcher, 1994), AIDS-patients (Newton, Leuchter, \& Miller, 1994), industrial workers exposed to a carbon disulfide (Rudolf, Jakisch, \& Volket, 1996), and patients with various types of dementia-associated with multiple sclerosis, Alzheimer's disease, and others (Comi \& Leocani, 1999; Dunkin, Leuchter, Newton, \& Cook, 1994; Locatelli, Cursi, Liberati, Franceschi, \& Comi, 1998). Our previously published data have also demonstrated the high sensitivity of EEG coherence analysis to determine the functional brain state in Chernobyl liquidators, including a longitudinal study to determine the delayed consequences of the Chernobyl accident (Zhavoronkova, Kholodova, Zubovsky, Gogitidze, et al., 1995; Zhavoronkova, Kholodova, Zhubovsky, Smirnov, et al., 1995; Zhavoronkova et al., 2006). In the present study, we used both EEG power and coherence analysis, which provides important information about the functional state of the human brain and cortical-cortical and cortical-subcortical connectivity, whereas the literature as a rule offers data 
about EEG power analysis in Chernobyl clean-up workers (Loganovsky \& Yuryiev, 2001, 2004; Nyagu et al., 1992; Nyagu, Loganovsky, \& Chuprovskaja, 1997; Nyagu, Loganovsky, \& Yuryev, 1999).

During last few years, the hypothesis of premature ageing in Chernobyl clean-up workers was proposed by several authors who suggested that radiation was a key factor influencing the speed of human biological ageing. In a study of Russian investigators, vegetative and somatic measures in various groups of people including Chernobyl liquidators were compared to groups of people including healthy age-matched controls. It was found that the biological age of the Chernobyl liquidators was 60-65 years, while their real age was below 50 (Alishev et al., 2006). Moreover, an unbalance and disturbances in the antioxidant system, which are characteristic of ageing organisms, produced by a low dose of radiation, was found in Chernobyl liquidators (Burlakova, 2006). Psychological studies based on the evaluation of the higher mental functions, intellectual activity, and personality scores in the Minnesota Multiphasic Personality Inventory (MMPI) revealed personality disorders in the Chernobyl survivors at the late stage after the clean-up, which were similar to those of old people: hypochondria, hysterical tendencies, egocentrism, and senile mentality (Kholodova, Ryzhov, \& Zhavoronkova, 2005; Kholodova, Zhavoronkova, Ryzhov, \& Kuznetsova, 2007). Clinical profiles (cerebral atherosclerosis, arterial hypertension, dyscirculatory encephalopathy, broncho-pulmonary, and others) and some neuropsychological parameters (disorders of countinglogical skill) of the Chernobyl survivors measured at the late stage after the clean-up were also similar to those of old people (Kholodova et al., 2007). EEG signs of premature brain ageing in Chernobyl clean-up workers were described in our previous studies but they were insufficient (Zhavoronkova et al., 2006).

The aim of the present study was to determine the EEG power and coherence parameters in Chernobyl survivors without radiation sickness at the diverse stages after the Chernobyl clean-up works and to compare them with agematched healthy controls in order to test the brain ageing hypothesis.

\section{Method}

\section{Participants}

The Rentgenoradiological Center of the Ministry of Health of the Russian Federation is the main referral center of the survivors of the Chernobyl accident of the Russian Federation. For 17 years (from 1990 to 2006), 189 persons (males, right-handers, aged from 22 to 49 years, mean age $30.7 \pm 4.3$ at the time of the Chernobyl accident) were examined by the Expert Committee in the
Rentgenoradiological Center and in the Institute of Higher Nervous Activity and Neurophysiology of the Russian Academy of Sciences. The clinical status of the Chernobyl survivors was examined in order to evaluate their capacity to engage in professional activity. Out of these 189 persons, 178 from various locations of the Russian Federation were included in the cross-sectional study because they had been examined in the Rentgenoradiological Center at different times. Out of these 178 Chernobyl survivors, 43 persons (mean age 34.7 \pm 5.4 ) were examined in 1990-1992; 46

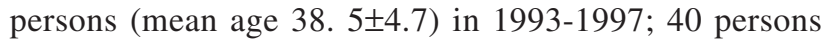
(mean age 43.5 \pm 3.5 ) in 1998-2002; and 49 persons (mean age 48.7 \pm 5.3 ) in 2003-2006. Those who lived in Moscow (11 persons) participated in the longitudinal study. Before the Chernobyl clean-up work, all these people had been diagnosed as healthy, and this information was recorded in their medical records. The individual dose of radiation for the Chernobyl survivors was not evaluated, and only the collective dose was reconstructed. None of the Chernobyl workers examined had been diagnosed with acute radiation sickness after the Chernobyl clean-up work. As a control group, 63 healthy volunteers (males, right-handers, 25-60 years of age) were selected (1990-2006). They were divided into subgroups that were age-matched with the Chernobyl survivor subgroups. All participants gave their written consent to participate in the investigations. The personal data of each patient such as sex, handedness, age, education, collective dose of radiation, and the duration of the cleanup work in the Chernobyl area were entered in the database for comparison with the data of the healthy participants, matched in age and education. The guidelines of the Helsinki protocol were applied.

\section{Measures}

EEG recording and analysis. The EEG was recorded on OTE Biomedical (Italy) or Nihon Cohden (Japan) equipment, using a time of constant of $0.3 \mathrm{~s}$ and the high frequency cut-off was $30 \mathrm{~Hz}$. The 19 chlorine-silver electrodes were placed according to the International 10-20 system at Fp1, Fp2, F3, F4, C3, C4, P3, P4, O1, O2, F7, F8, T5, T6, T3, $\mathrm{T} 4, \mathrm{Cz}, \mathrm{Pz}$ and the additional channel was used to record the electro-oculogram (for vertical eye movements). All electrode impedances were kept under $50 \mathrm{k} \Omega$ and all channels were digitized at the rate of $128 \mathrm{~Hz}$. Linked earlobes served as the reference electrode. The use of linked earlobes reference has proven to be adequate for coherence analysis and asymmetry studies of EEG parameters (Nunez, 1981; Rappelsberger \& Petsche, 1988). We processed signals from several montage schemes, including standard monopolar and bipolar montage, although the focus of this study was a monopolar montage.

Each recording lasted from 60 to $100 \mathrm{~s}$ in the state of rest with closed eyes, open eyes, and during standard functional tasks. In the present study, only resting EEGs 
with closed eyes were used for the analysis. The EEGs were stored for off-line processing. Artifacts (blinks, muscle artifacts, and others) were eliminated from further computation based on visual inspection. Artifact-free 2.56s epochs (at least 10) were chosen for future analysis. Each epoch was Fourier-transformed to calculate averaged power- and cross-power spectra, and averaged crossspectra. Data reduction of the spectra was performed by averaging adjacent spectral lines to obtain broad band parameters for six frequency bands: delta $(0.5-4 \mathrm{~Hz})$, theta $1(4-6 \mathrm{~Hz})$, theta $2(6-8 \mathrm{~Hz})$, alpha $(8-13 \mathrm{~Hz})$, beta $1(13-$ $20 \mathrm{~Hz})$, and beta $2(20-30 \mathrm{~Hz})$. The mean frequency of the alpha band in occipital, parietal and central areas was calculated as a sum of the frequency for leads $\mathrm{O} 1, \mathrm{O} 2$, P3, P4, C3, and C4 and afterwards was divided into 6 . EEG coherences were calculated for 26 of intrahemispheric and 8 interhemispheric pairs. Averaged coherence for all spectral bands was also used in the analysis (Rusinov et al., 1987). Finally, integral EEG coherence (Ca) for all averaged intrahemispheric coherence in the resting state was calculated for patients and healthy subjects by the formula:

$$
\mathrm{Ca}=\frac{1}{\mathrm{n}}\left[\frac{\mathrm{Coh}_{\sum_{l_{1}}}-\mathrm{Coh}_{\sum_{r_{1}}}}{\mathrm{Coh}_{\sum_{l_{1}}}+\mathrm{Coh}_{\sum_{r_{1}}}}+\ldots+\frac{\mathrm{Coh}_{\sum_{l_{\mathrm{n}}}}-\mathrm{Coh}_{\sum_{r_{\mathrm{n}}}}}{\mathrm{Coh}_{\sum_{l_{\mathrm{n}}}}+\mathrm{Coh}_{\sum_{r_{\mathrm{n}}}}}\right],
$$

where Coh 1 and Coh $\mathrm{r}$ are the averaged coherence for symmetrical intrahemispheric pairs of the left and right hemisphere; $1,2, \ldots$ are the ordinal numbers of the pairs, and $n$ is the number of pairs. This approach was used in our previous studies for estimating the level of the brain functional state during wakefulness and sleep in healthy subjects. Healthy right-handed subjects had positive values of integral $\mathrm{Ca}$ in the state of rest, and their values decreased during sleep and were restored to positive values after awakening. In neurosurgical patients with the organic brain damage, values of the $\mathrm{Ca}$ did not change without special treatment and had specific values in cases with left or right hemisphere damage (Zhavoronkova, 2006; Zhavoronkova, Kholodova, Zubovsky, Gogitidze, et al., 1995).

\section{Statistical Analyses}

Statistical analysis included the calculation of the means, standard deviation, and standard error of age and EEG parameters in all examined groups. The significance of the differences of EEG parameters was estimated between the subgroups of age-matched controls and Chernobyl survivors at different stages after the Chernobyl accident using paired Student's $t$-test for independent samples from the statistical program Statistica 6.0. ANOVAs (one-way and two-way dispersion analysis) were also computed for comparison of the Chernobyl and control group data.
Results

Visual inspection and quantitative EEG power mapping was carried out, and analysis of mean frequency and averaged EEG power of alpha band in occipital, parietal, and central areas was performed. This analysis revealed that, in healthy aged-matched controls, the corresponding values of the alpha band frequency were $10.01 \pm 0.3 \mathrm{~Hz}$, and the averaged power was $75 \pm 17 \mathrm{mv}^{2}$, and this did not change significantly in healthy subjects aged 30 to 50 . Most of the Chernobyl clean-up workers showed, while in resting state (eyes closed), three abnormal EEG patterns, as indicated by the calculation of the mean frequency and averaged power of alpha band. The first EEG abnormal pattern was characterized by decreased frequency (mean values $8.3 \pm 0.3$ $\mathrm{Hz}$ ) and increased power in alpha- and theta-bands, and was named slow hypersynchronous (Figure $1,1^{\text {st }}$ column). In Chernobyl survivors with this EEG pattern, the power of the alpha band ranged from 100 to $415 \mathrm{mv}^{2}$ with a forward shift to the central and frontal areas. The averaged values of power in Chernobyl survivors with a slow hypersynchronous pattern were $195 \pm 47 \mathrm{mv}^{2}(p<.01$ compared to healthy age-matched individuals). This EEG pattern was observed in Chernobyl workers 3-5 years after the clean-up. The second EEG pattern was characterized by similar topographic abnormalities for fast alpha waves (mean values of frequency $11.5 \pm 0.5 \mathrm{~Hz}$, averaged values of power $132 \pm 35 \mathrm{mv}^{2}, p<.05$ ), and was named fast hypersynchronous and also was observed 3-5 years after the clean-up (Figure $1,2^{\text {nd }}$ column). The third EEG pattern revealed an overall lower power in alpha band (mean values of frequency $9.3 \pm 0.4 \mathrm{~Hz}$, averaged values of power $22 \pm 7 \mathrm{mv}^{2}, p<.01$ ). This pattern was observed in Chernobyl workers over ten years after the clean-up and was named flat (Figure 1, third column).

The results of the estimation of the Chernobyl clean-upworkers' number of different EEG patterns in the periods from 1990 to 2006 are presented in Figure 2 and Table 1. One-way ANOVA (Pearson's $\chi^{2}$ ) showed that the relative frequency of occurrence of the different EEG patterns has changed over the last 20 years $\left(\chi^{2}(6)=17.25, p=.008\right)$. The relative frequency of occurrence of the slow hypersynchronous EEG type did not change over the last years. The data from the one-way ANOVA support these results for frequency of occurrence of events with high probability, $F(3,170)=0.13, p=.94$. During the 1990-2006 period, the frequency of occurrence of the fast hypersynchronous EEG type decreased, while the frequency of occurrence of the flat EEG pattern increased. These data were supported by the one-way ANOVA for the frequency of occurrence of the second EEG type in comparison to the third, $F(3,94)=6.82, p<.001$, as well by as the values of Spearman's range coefficients for cross-classification tables ( 2 types of EEG_ 4 time points), $\rho=-0.39, p<.001$ ). The values of $\chi^{2}$ for this table, $\chi^{2}(3)=17.52, p<.001$, also 
"slow hypersynchronous"

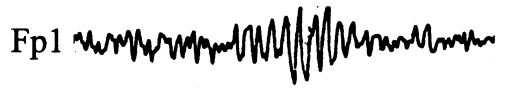

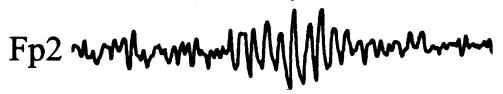

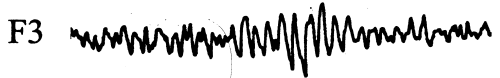

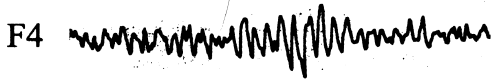

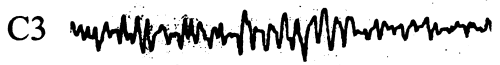

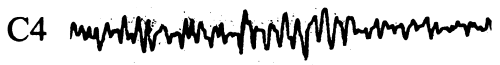

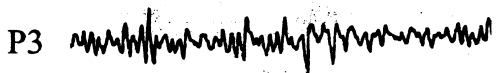

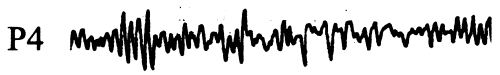

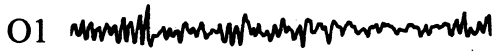

O2 num

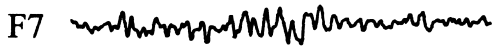

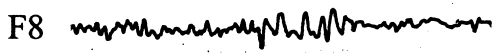

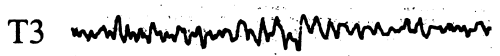

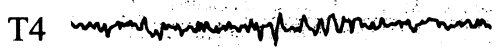

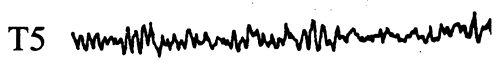

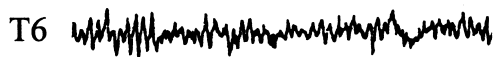

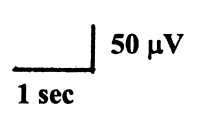

"fast hypersynchronous"

"flat"

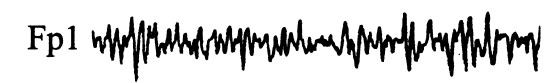

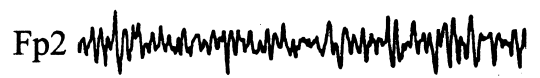

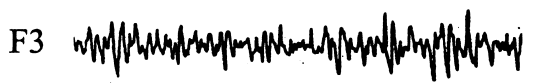

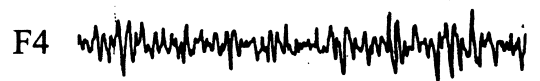

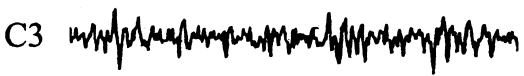

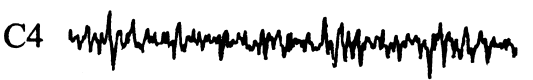

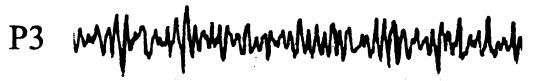

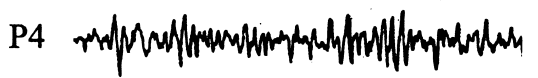

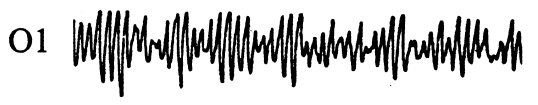

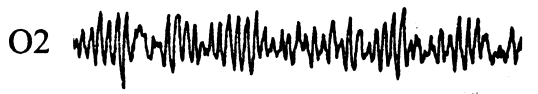

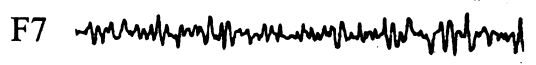

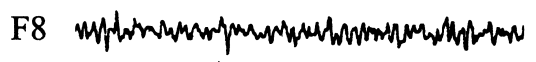

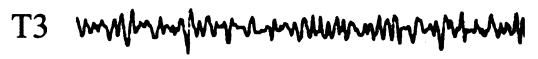

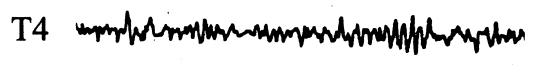

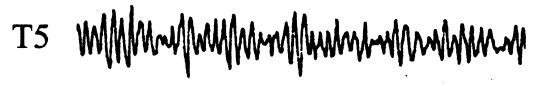

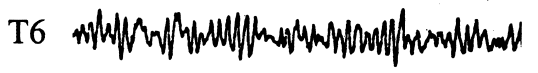
$\varlimsup_{1 \mathrm{sec}}^{50 \mu \mathrm{V}}$

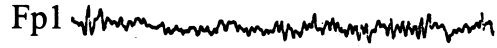

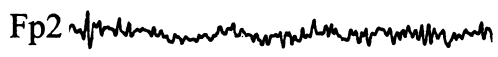

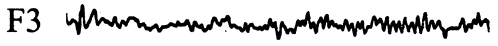

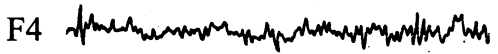

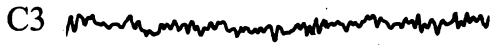

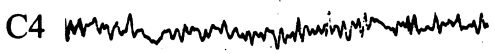

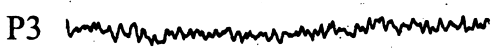

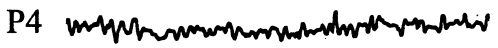

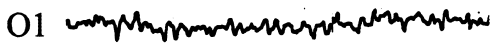

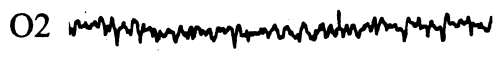
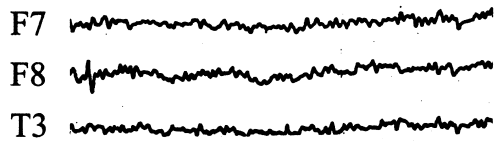

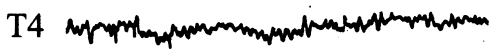

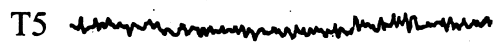

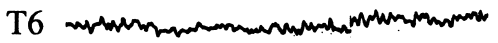
$\prod_{1 \mathrm{sec}} 50 \mu \mathrm{V}$

Figure 1. Examples of abnormal EEG patterns in Chernobyl clean-up workers.

A = Slow hypersynchronous EEG of Chernobyl survivor M (29 years old); $b$ = fast hyprsynchronous EEG of Chernobyl survivor G (38 years old); $\mathrm{c}=$ flat EEG of Chernobyl survivor S (45 years old).

Table 1

Table of Cross-classification for two Types of EEG and for four Time Points

\begin{tabular}{|c|c|c|c|c|}
\hline & $\begin{array}{c}\text { Slow hypersynchronous } \\
\text { EEG (Type 1) }\end{array}$ & $\begin{array}{c}\text { Fast hypersynchronous } \\
\text { EEG (Type 2) }\end{array}$ & $\begin{array}{r}\text { Flat EEG } \\
\text { (Type 3) }\end{array}$ & Total \\
\hline 1990-1992 & 20 & 12 & 6 & 38 \\
\hline Row \% & $52.63 \%$ & $31.57 \%$ & $15.79 \%$ & \\
\hline 1993-1997 & 20 & 9 & 17 & 46 \\
\hline Row \% & $43.47 \%$ & $19.56 \%$ & $36.96 \%$ & \\
\hline 1998-2002 & 17 & 8 & 15 & 40 \\
\hline Row \% & $42.50 \%$ & $20.00 \%$ & $37.50 \%$ & \\
\hline 2003-2006 & 21 & 3 & 25 & 49 \\
\hline Row \% & $42.85 \%$ & $6.12 \%$ & $51.02 \%$ & \\
\hline Total & 78 & 32 & 63 & 173 \\
\hline
\end{tabular}


Table 2

Two-way ANOVA for Mean Values of Ca of EEG Coherence in Chernobyl Survivors and Control Groups at Different Time Points

\begin{tabular}{lccr}
\hline & $d f$ & $F$ & $p$ \\
\hline Intercept & 1 & 409.6817 & .000000 \\
Group & 1 & 694.6544 & .000000 \\
Series & 3 & 20.6556 & .000000 \\
Group*Series & 3 & 0.6922 & .557531 \\
Error & 257 & & \\
\hline
\end{tabular}

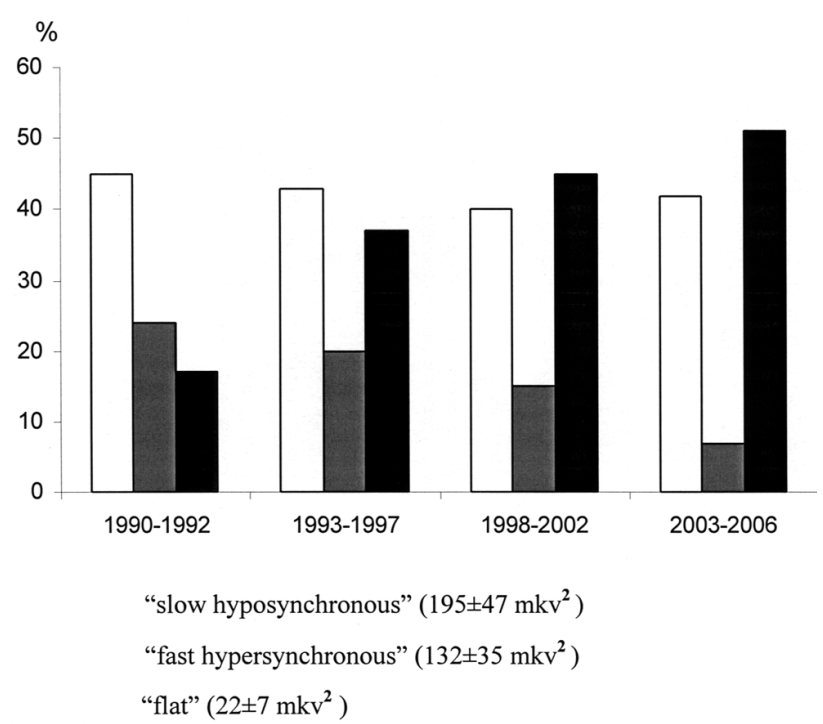

Figure 2. Number of Chernobyl clean-up workers with different abnormal of EEG patterns (in \%) recorded from 1990 to 2006.

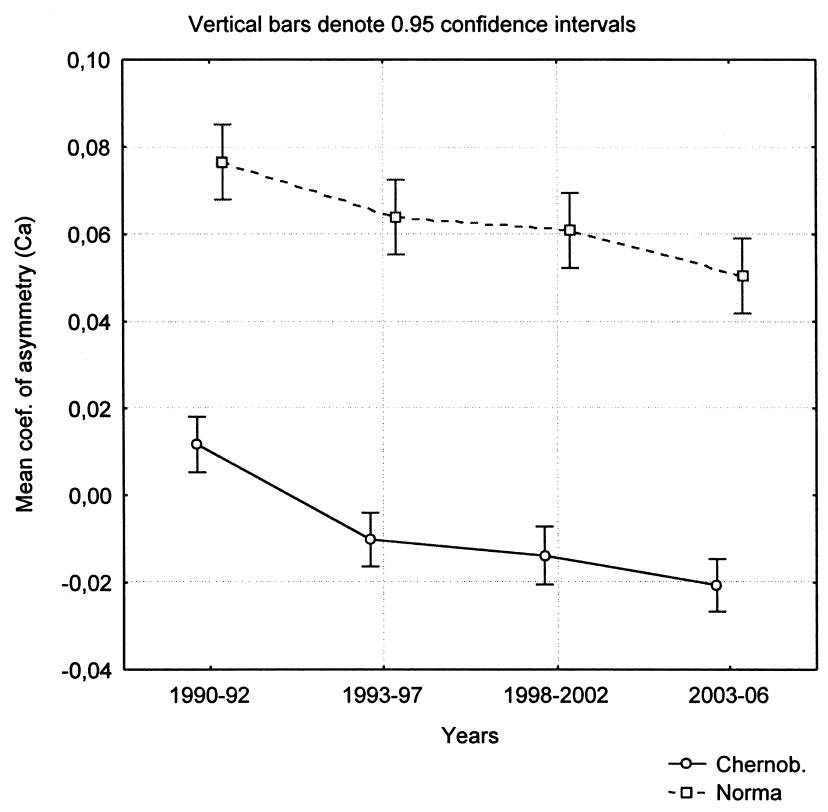

Figure 3. Mean values of integral asymmetry coefficients $(\mathrm{Ca})$ of EEG coherence in Chernobyl clean-up workers $(n=178)$ and agematched healthy subjects $(n=63)$ in diverse stages after clean-up work in Chernobyl. revealed significant differences in the frequency of occurrence of the second and the third EEG patterns at different time points of studies. Post-hoc Duncan's test yielded significant differences $(p<.05)$ for the frequency of occurrence of the second EEG pattern in comparison to the third one. Thus, statistical analysis showed that the number of Chernobyl survivors with fast hypersynchronous EEG decreased significantly at the late stage after the clean-up, whereas the number of Chernobyl survivors with flat EEG increased. Moreover, in the 1990-1992 period, the normal EEG pattern was observed in $13 \%$ of the Chernobyl survivors examined whereas, in the later stages, only pathological EEG patterns were observed in all Chernobyl survivors.

EEG coherence analysis showed that, in healthy individuals, EEG coherence values were higher in the left hemisphere and, consequently, the integral Ca calculated from all the intrahemispheric pairs in the left and right hemispheres had positive values (Figure 3). In Chernobyl survivors, the values of intrahemispheric EEG coherence were notably reduced in the left hemisphere, and the values of $\mathrm{Ca}$ were lower or close to zero 3-5 years after the clean-up. Two-way ANOVA showed that both factors (groups of persons and time points) had a significant effect on the mean values of $\mathrm{Ca}$ of EEG coherence, whereas the interaction between these factors was nonsignificant (Figure 3 and Table 2).

Analysis of differences between $\mathrm{Ca}$ mean values using Newman-Keuls test $(p<.05)$ showed that Ca values were lower at all time points in the Chernobyl survivors compared to the control groups, whereas the systematic decrease of $\mathrm{Ca}$ values was observed both in Chernobyl survivors and older controls groups.

Healthy controls compared to Chernobyl survivors at different time points after the clean-up works displayed higher values of interhemispheric EEG coherence in the frontal-frontal pairs (Figure 4 and Table 3 ). Figure 4 shows that, in the Chernobyl survivors, the frontal interhemispheric EEG coherences were markedly reduced. The strongest reduction was observed in the Chernobyl survivors 10 or more years after the accident. In contrast, interhemisperic EEG coherence in central areas showed diverse changes in the Chernobyl survivors measured at early and late time points. Three to five years after the clean-up, mainly increased average coherence values were obtained, whereas reduced EEG coherence measures were generally reduced more markedly 10 or more years after the clean-up. 
Table 3

Dispersion Analysis (one-way ANOVA) for Values of Interhemispheric EEG Coherence for Different Electrode Pairs for Chernobyl Survivors and Control Groups

\begin{tabular}{lccrr}
\hline & $d f 1$ & $d f 2$ & $F(d f 1, d f 2)$ & \multicolumn{1}{c}{$p$} \\
\hline Fp1-Fp2 & 4 & 218 & 86.1034 & .000000 \\
F3-F4 & 4 & 218 & 79.5244 & .000000 \\
C3-C4 & 4 & 218 & 215.0889 & .000000 \\
P3-P4 & 4 & 218 & 153.3070 & .000000 \\
O1-O2 & 4 & 218 & 75.6311 & .000000 \\
F7-F8 & 4 & 218 & 248.8751 & .000000 \\
T3-T4 & 4 & 218 & 15.7960 & .000000 \\
T5-T6 & 4 & 218 & 98.3370 & .000000 \\
\hline
\end{tabular}

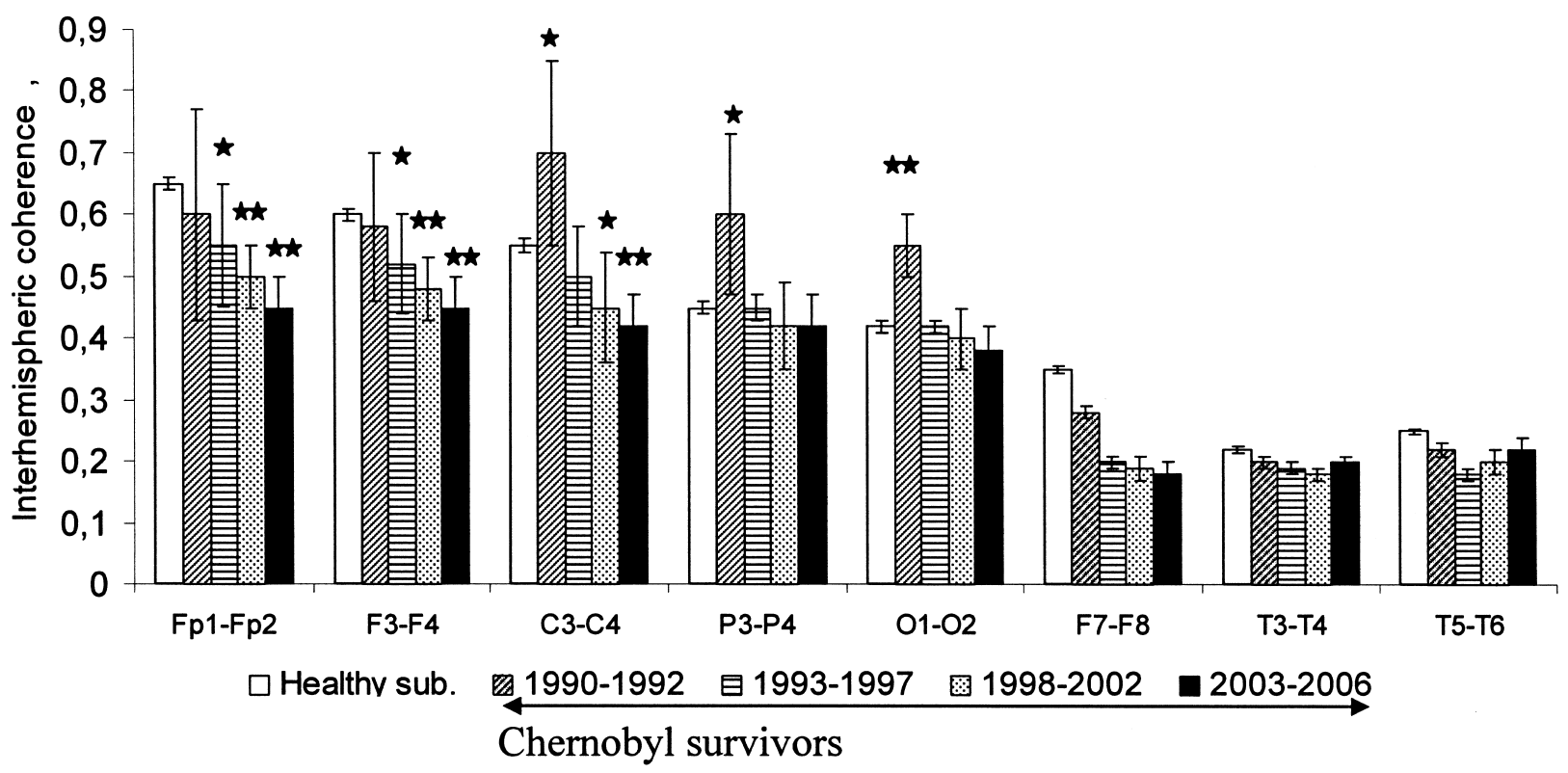

Figure 4. Interhemispheric EEG coherence in Chernobyl clean-up workers $(n=178)$ and in age-matched healthy subjects $(n=63)$ at different time points after clean-up work in Chernobyl.

The bars show averaged EEG coherence of healthy persons and Chernobyl survivors for different cortical areas.

$*$ Significant differences $(*$ different range $p<.05$. ** different range $p<.01$ ).

One-way ANOVAs for each of electrode pairs showed that, for all electrodes, there were significant differences between the compared groups (healthy controls and Chernobyl survivors) in the average EEG coherence values.

ANOVA of interhemispheric EEG coherence changes for electrode pairs at different time points was performed, comparing Chernobyl survivors and the normal groups. The 1990-1992 values of EEG coherence in the Chernobyl survivors can be divided into three groups. In the first group, EEG coherence in the Chernobyl survivors (Newman-Keuls procedure with a probability of error of $p<.05$ ) exceeded the norm and then actually decreased year by year (C3-C4, P3-P4, and O1-O2). In the second group (Fp1-Fp2, F7-F8), even in 1990-1992, EEG coherence in the Chernobyl survivors was already either significantly or as a trend (F3F4) below norm, and then it decreased significantly from term to term (except for pair F7-F8). In the third group (T3T4 and T5-T6), EEG coherence was initially significantly below norm; then, for 10 years, their values increased, and at the later period, their values even exceeded the norm.

Statistical analysis of the longitudinal EEG study results was not carried out because the groups of Chernobyl survivors included in this section of the study were small. However, EEG changes in this section showed the main trend described in the cross-sectional study. The individual samples of EEG study are presented in Figure 5 and show the transformation of the fast hypersynchronous EEG pattern into the flat one at the later stage after the clean-up of Chernobyl. 

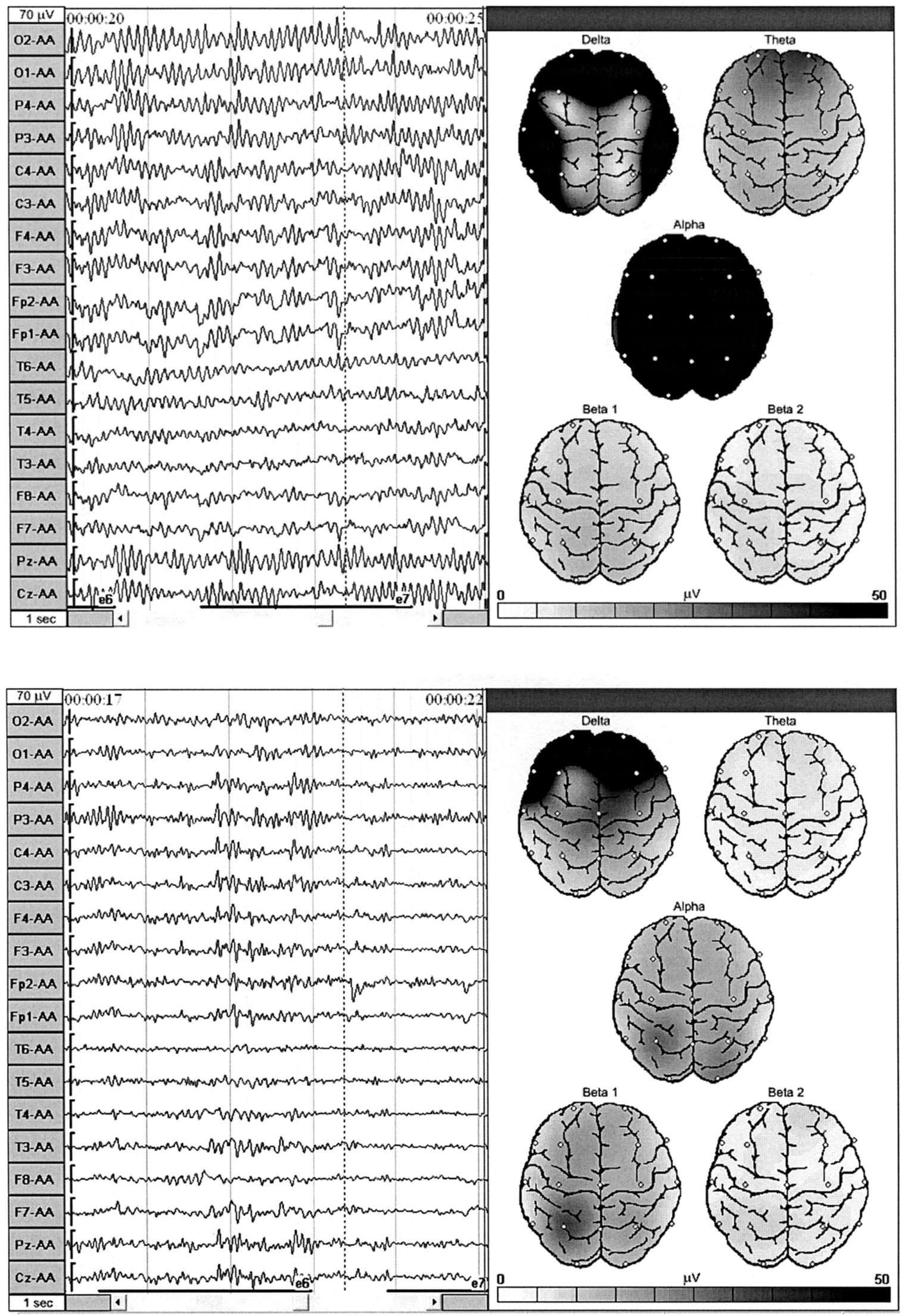

Figure 5. Examples of EEG pattern in Chernobyl survivor K(a) in 1991 (34 years old) and in 1999 (b). 


\section{Discussion}

In the present study, we found in Chernobyl clean-up workers who were around 30 years old at the time of accident and below 50 (at the end of this study) presented low values of EEG power in alpha band ten years after the Chernobyl clean-up. These results are accordance with previous data of Ukrainian researchers (Loganovsky \& Yuryev, 2001, 2004). Similar EEG power signs were obtained by other authors in individuals over 60 years of age (Duffy \& Albert, 1984; Klass \& Brenner, 1995; Klimesch, 1999; Marciani et al., 1994; Pierce et al., 2000). Moreover, very similar EEG abnormalities have been also obtained in people with dementia of diverse origin (Ponomareva, Selesneva, \& Jarikov, 2003; Szeilies, Mielke, Herholz, \& Heiss, 1994). Thus, EEG abnormalities in the Chernobyl clean-up workers can be regarded as an indicator not only of premature brain ageing but also of a pre-clinical stage of dementia.

EEG coherence abnormalities, that is, maximal reduction of interhemispheric EEG coherence in the frontal areas and a cortical projection of the frontal lobes, have been observed in Chernobyl survivors at late time points after the Chernobyl clean-up. The same EEG abnormalities are characteristic of old people's brains (Klass \& Brenner, 1995; Marciani et al., 1994; Ponomareva, Mitrofanova, Androsova, \& Pavlova, 2007). On the other hand, similar changes in EEG have been described in brain lesions (traumatic and vascular) and in diverse forms of dementia (Comi \& Leocani, 1999; Locatelli et al., 1998) because the frontal lobes are particularly sensitive to the damaging effect of various factors (Sachdev, 2004).

In healthy humans, brain asymmetry increases with age, reaching optimal values in adulthood, and it decreases in old age (Bragina \& Dobrokhotova, 1988; Crow, 2005). In the present study, we observed reduced brain asymmetry (as a result of a marked decrease of EEG coherence in the left hemisphere) in survivors below 50 years of age at the late stage after the Chernobyl clean-up. The data presented in this study correlate with the concept of HAROLD (hemispheric asymmetry reduction in older adults). This model proposes that brain asymmetry tends to be less lateralized in older subjects than in young persons (Cabeza, 2002).

An important fact that appeared at the present study was the presence of two stages in the development of EEG abnormalities that were found in the Chernobyl clean-up workers. In the early stage after the Chernobyl clean-up, a prominent increase of EEG coherence in central areas, especially in theta band, was observed in the present and in previous studies (Zhavoronkova, Kholodova, Zubovsky, Gogitidze, et al., 1995). These data agree with the viewpoint of some authors, indicating that EEG coherence, especially between hemispheres for theta bands, might be interpreted as a cortical differentiation from subcortical structures, including limbic structures (Boldyreva et al., 2007; Comi
\& Leocani, 1999; Newton et al., 1994). These EEG signs may be a reflection of both radiation and stressor factors and can be used to understand the post-radiation after-effect mechanisms. The data presented allowed us to propose that, at the initial stage after exposure to radiation, hyperactivity of subcortical structures (possibly the limbic and diencephalic complex) is predominant, reflecting compensatory brain activation. In contrast to the early stage, at the later time point after the clean-up, EEG coherence measures in Chernobyl survivors were reduced, especially in the frontal areas in alpha and beta bands (Zhavoronkova, Kholodova, Zubovsky, Gogitidze, et al., 1995; Zhavoronkova et al., 1999; 2006). These EEG signs and data about sources of spectral EEG bands (Lopez da Silva, 1991) allowed us to propose that the predominant cerebral cortical dysfunction and may be a sign of brain maladaptation in the late stage after the Chernobyl clean-up. The dynamics of brain ageing described in the Chernobyl clean-up workers differs from those of healthy people and assumes "abnormal" or "pseudo" ageing as a result of radiation after-effect.

Thus, the results of the present EEG study revealed two stages of after-effects in the brains of the Chernobyl cleanup workers, forming low levels of EEG alpha power at the late stage, a decrease of EEG coherence most prominent in the frontal brain areas, and reduced brain asymmetry in comparison to age-matched healthy persons. Previous clinical, psychophysiological, and immunological studies of the markers of the consequences of the Chernobyl accident allowed us to propose the hypothesis of premature ageing of the whole organism in individuals who took part in the clean-up work of Chernobyl. Our EEG data may provide additional support to this hypothesis of premature brain ageing in Chernobyl survivors as result of radiation after-effect.

\section{References}

Alishev, N.V., Svistov, A.S., Ryzhman, N.N., Drabkin, B.A., Vashkevich, A.A., \& Nikolaeva, N.A. (2006). Indeksy biologicheskogo vozrasta ran'negostarenia likvidatorov posledstvii radiacionnih katastrof [The indices of biological age and accelerated aging in the liquidators of the consequences of radiation emergency]. Adv. Gerontology, 18, 110-124.

Boldyreva, G.N. (2000). Electricheskaja aktivnost' mozga cheloveka pri porazhenii diencefal'nih i limbicheskih struktur [Electrical activity of human brain in lesions of the diencephalic and limbic structures] Moscow: Nauka.

Boldyreva, G.N., Zhavoronkova, L.A., Sharova, E.V., \& Dobronravova, I.S. (2007). Electroencephalographic intarcentral interaction as a reflection of normal and pathological human brain activity. Spanish Journal of Psychology, 10, 167-177.

Bragina, N.N., \& Dobrokhotova, T.A. (1988). Funkcional'naja asimmetria i psihopatologia pri fokal'nih povrezhdenjah mozga [Functional asymmetry and psychopathology of the focal brain lesions]. Moscow: Meditsina. 
Burlakova, E. (2006). Scientific principles of the damaging effect of radiation on the state of health of the general population. Abstracts of International Congress: Chernobyl - 20 years later. Berlin. ECRR European Committee on Radiation Risk, 27-29.

Cabeza, R. (2002). Hemispheric asymmetry reduction in older adults: The HAROLD model. Psychological Aging, 17, 85-100.

Comi, G., \& Leocani, L. (1999). Neurophysiological imaging techniques in dementia. Italian Journal of Neurological Science, 20, S265-S269.

Crow, T.J. (2005). Losses and reversals of asymmetry in schizophrenia as studied in post-mortem brain. World Journal of Biological Psychiatry, 6, 58.

Davidov, B.I., Ushakov, B.I., \& Fedorov, V.P. (1991). Irradiation damage of the brain. Moscow: Energoizdat (Russian).

Duffy, F.H., \& Albert, M.S. (1984). Age-related differences in brain electrical activity of healthy subjects. Annals of Neurology, 16, 430-438.

Dunkin, J.J., Leuchter, A.F., Newton, T.F., \& Cook, I.A. (1994). Reduced EEG coherence in dementia: State or trait marker? Biological Psychiatry, 35, 870-879.

French, C.C, \& Beaumont, J.G. (1984). A critical review of EEG coherence studies of hemispheric function. International Journal of Psychophysiology, 1, 241-254.

Gluzman, D.F., Imamura, N., Sklyarenko, L.M., Nagornaya, V.A., Zavelevich, M.P., \& Simolet, M.L. (2006). Leukemias in cleanup workers diagnosed in the Ukrainian reference laboratory in 1996-2005: Different biological forms and their relative distribution. Abstracts of International Congress: Chernobyl - 20 years later. Berlin. ECRR European Committee on Radiation Risk, 53-54.

Kholodova, N.B., Ryzhov, B.N., \& Zhavoronkova, L.A. (2005). Narushenija visshih psihicheskih funkcii u Cherbil'skih likvidatorov [Disorders of higher mental functions in Chernobyl liquidators]. Zhurnal Nevropathol. Psykhiat.r Im. S.S. Korsakova, 105, 57-58.

Kholodova, N.B., Zhavoronkova, L.A., Ryzhov, B.N., \& Kuznetsova, G.D. (2007). Pezhdevremennoe starenie organizma I osobennosti ego projavlenija $\mathrm{v}$ ottdalennie sroki posle obluchenija malimi dozami [Preliminary aging of the organism and its development at the late period after exposure to low doses]. Dostishenija Gerontologii, 19, 48-55.

Kimeldorf, D., \& Hant, E. (1969). Deistvie ioniziruyuschei radiacii na funkcii nervnoi sistemi [Effect of ionizing radiation on the nervous system]. Moscow: Pease.

Klass, D.W., \& Brenner, R.P. (1995). Electroencephalography of the elderly. Journal of Clinical Neurophysiology, 12, 116-131.

Klimesch, W. (1999). EEG alpha and theta oscillations reflect cognitive and memory performance: A review and analysis. Brain Research Reviews, 29, 169-195.

Knyazeva, M.G., \& Innocenti, G.M. (2001). EEG coherence study in the normal brain and after early-onset cortical pathology. Brain Research Review, 36, 119-128.

Livanov, M.N. (1961). Nekotorie problemi deistviya ioniziruyuschei radiacii [Some aspects of ionizing radiation effect]. Moscow: Medicine.
Locatelli, T., Cursi, M., Liberati, D., Franceschi, M., \& Comi, G. (1998). EEG coherence in Alzheimer's disease. Electroencephalograpy and Clinical Neurophysiology, 106, 229-237.

Loganovsky, K.N., \& Loganovskaja, T.K. (2000). At issue: Schizophrenia spectrum disorders in persons exposed to ionizing radiation as a result of Chernobyl accident. Schizophrenia Bulletin, 26, 751-773.

Loganovsky, K.N., \& Yuryev, K.L. (2001). EEG patterns in persons exposed to ionizing radiation as a result of the Chernobyl accident: Part 1: Conventional EEG analysis. Journal of Neuropsychiatry and Clinical Neurosciences, 13, 441-458.

Loganovsky, K.N., \& Yuryev, K.L. (2004). EEG patterns in persons exposed to ionizing radiation as a result of the Chernobyl accident: Part 2: Quantitative EEG analysis in patients who had acute radiation sickness. Journal of Neuropsychiatry and Clinical Neurosciences, 16, 70-82.

Lopez da Silva, F.H. (1991). Neural mechanisms underlying brain waves: From neural membranes to networks. Electroencephalograpy and Clinical Neurophysiology, 79, 8189.

Marciani, M.G., Maschio, M., Spanedda, F., Galtagirone, C., Gigli, G.L., \& Bernardi, G. (1994). Quantitative EEG evaluation in normal elderly subjects during mental processes: Age-related changes. International Journal of Neuroscience, 76, 131-140.

Marosi, E., Harmony, T., Sanchez, L., Bernal, J., Reyes, A., Deleon, A.E.D., Rodriguez., M., \& Fernandez, T. (1992). Maturation of the coherence EEG activity in normal learning disabled children. Electroencephalograpy and Clinical Neurophysiology, 83, 350-357.

Meshkov, H.A., Rychov, N.I., Kuznetsova, G.D., Shlyk, G.G., Zhavoronkova, L.A., \& Kholodova, N.B. (1993). Ottadlennie posledstvia vozdeistbija radiacii na nevrologichesakii status [Late consequences of irradiation influences on neurological status]. Voenno-Medistinskii Zhurnal, 4, 7-73.

Michelogianis, S., Paritsis, N., \& Trikas, P. (1991). EEG coherence during hemispheric activation in schizophrenia. European Archives of Psychiatry and Clinical Neuroscience, 24, 31-34.

Mickley, G.A. (1987). Psychological effects of nuclear warfare. In J.J. Conklin \& R.I. Walker (Eds.), Military radiobiology (pp. 303-319). San Diego, CA: Academic Press.

Mironov, V., Tretyakevich, S., \& Zhuravkov, V. (2006). Thyroid doses and radiation risk of thyroid cancer for inhabitants of Belarus following the accident in the Chernobyl NPP. Abstracts of International Congress: Chernobyl - 20 years later. Berlin. ECRR European Committee on Radiation Risk, 66-67.

Nagase, Y., Okubo, Y., Matsura, M., Kojima, T., \& Toru, M. (1992). EEG coherence in unmedicated schizophrenia patients topographic study of predominantly never medicated cases. Biological Psychiatry, 32, 1028-1034.

Newton, T.F., Leuchter, A.F., \& Miller, H. (1994). Quantitative EEG in patients with AIDS and asymptomatic HIV infection. Clinical Electroencephalography, 25, 18-25.

Nunez, P. L. (1981). Electric fields of the brain: The neurophysics of EEG. New York: Oxford University Press. 
Nyagu, A.I., Noschenko, A.G., \& Loganovsky, K.N. (1992). Ottdalennie posledstvija psikhogennogo i radiazionnogo faktorov avarii na Chernobylskoi AES na funkcional'noe sostojanie golovnogo mozga cheloveka [Long-term consequences of psychogenic and radiation factors of the Chernobyl accident in the functional state of the human brain]. Zhurnal Nevropathologii i Psykhiatrii Im. S.S. Korsakova, 92, 72-78.

Nyagu, A.I., Loganovsky, K.N., \& Chuprovskaja, N.Yu. (1997). Postradiazionnaja encefalopatija $v$ otdalennii period ostroi luchevoi bolezni [Postradiation encephalopathy at the remote period of acute radiation sickness]. Ukrainian Medical Journal, 2, 33-44.

Nyagu, A.I., Loganovsky, K.N., \& Yuryev, K.L. (1999). Psychophysiological aftermath of irradiation. Journal of Radiation Medicine, 2, 3-24.

Petsche, H. (1996). Approaches to verbal, visual and musical creativity by EEG coherence analysis. International Journal of Psychophysiology, 24, 145-159.

Pierce, T.W., Kelly, S.P., Watson, T.D., Replogle, D., King, J.S., \& Pribram, K.H. (2000). Age differences in dynamic measure of EEG. Brain Topography, 13, 127-134.

Ponomareva, N.V., Mitrofanova, A.A., Androsova, L.V., \& Pavlova, O.A. (2007). Vlijanie stressa na mezhpolusharnoe vzaimodeistvie pri nomal'nom starenii i bolezni Alzheimera. [Influence of stress on the interhemispheric interaction during normal ageing and in patients with Alzheimer's disease]. Journal of Asymmetry, 1, 20-26

Ponamareva, N.V., Selesneva, N.D., Jarikov, G.A. (2003). EEG alterations in subjects at high familial risk for Alzheimer's disease. Pharmacoencephalography, 48, 152-159.

Rappelsberger, P., \& Petsche, H. (1988). Probability mapping: Power and coherence analyses of cognitive processes. Brain Topography, 1, 46-54.

Rudolf, M., Jakisch, D., \& Volke, H.J. (1996). Factoren- und diskriminanzanalitische Auswergtung komponentenbezogener Koharenzen des EEG zur Fruherkennung neurotoxischer Schadigungen [Factor and discriminant analysis of coherencerelated EEG parameters for ditection of neurotoxin impairment]. EEG-EMG Zeitschrift fur Elektroenzephalografie, Elektromyografie und verwandte Gebiete, 28, 96-102.

Rusinov, V.S., Grindel, O.M., Bodyreva, G.N., \& Vakar E.M. (1987). Biopotencialy mozga cheloveka. Matematicheskii analiz [Biopotentials of the human brain. Mathematical analysis] Moscow: Meditsina.

Sachdev, P.S. (2004). The cognitive profile of vascular cognitive impairment. Abstracts of $5^{\text {th }}$ International Congress of Neuropsychiatry, Athens, 17.

Sharova, E.V. (1999). Adaptivno-kompensatornie perestroika bioelecticheskoi aktivnosti mozga cheloveka pri povrezhdenii stvolovih obrazovanii [The adaptive-compensatory reorganizations of the human brain's bioelectrical activity at brainstem damage]. Summary of doctoral dissertation. Moscow: Institute of Higher Nervous Activity and Neurophysiology RAS.
Szeilies, B., Mielke, R., Herholz, K., \& Heiss, W.-D. (1994). Quantitative topographic EEG compared to FDG PET for classification of vascular and degenerative dementia. Electroencephalography and Clinical Neurophysiology, 91, 131-139.

Thatcher, R.W. (1994). Cyclic cortical reorganization, origins of human cognitive development. In G. Dawson \& K. Fisher (Eds.), Human behaviour and the development brain (pp. 232266). New York: Guilford Press.

Tucker, D.M., Roth, D.L., \& Bait, T.B. (1986). Functional connections among cortical regions: Topography of EEG coherence. Electroencephalography and Clinical Neurophysiology, 63, 242-250.

Yaar, I., Ron, E., \& Modan, B. (1982). Long-lasting cerebral functional changes following moderate dose X-radiation treatment to the scalp in childhood: An EEG power spectral study. Journal of Neurology, Neurosurgery \& Psychiatry, 45, 166-169.

Zhavoronkova, L.A. (2006) Parvshi-levshi: mezhpolusharnaja asymmetrija eletricheskoi aktivnosty mozga cheloveka [Righthanders and left-handers: Interhemispheric asymmetry of the human brain electrical activity. Moscow: Nauka.

Zhavoronkova L.A., Gogitidze N.V., \& Kholodova N.B. (1999). Longitudinal EEG coherence and neuropsychological examination of the brain functional state in dextral and sinistral Chernobyl patients. Neuroimage, 10, A-59.

Zhavoronkova, L.A., Kholodova, N.B., Zubovsky, G.A., Gogitidze, N.V., \& Koptelov, Yu.M. (1995). EEG power mapping, dipole source and coherence analysis in Chernobyl patients. Brain Topography, 8, 161-168.

Zhavoronkova, L.A., Kholodova, N.B., Zhubovsky, G.A., Smirnov, Yu.N., Koptelov, Yu.M., \& Ryzhov, N.I. (1995). Electroencephalographic correlates of neurological disturbances at remote period of the effect of ionizing radiation (sequel of the Chernobyl NPP Accident). Neuroscience and Behavioral Physiology, 25, 142-150.

Zhavoronkova, L.A., Lavrova, T.P., Belostotskii, A.V., Kholodova, N.B., Skoriatina, I.G., \& Voronov, V.P. (2006). Posradiacionnie narushenija regionarno-chastotnkh kharakteristik kogerentnosti EEG pri kognitivnoi dejanel'nosti (posledsvija avarii na Cherbilskoi AES). [Impairment of space-frequency parameters of EEG coherence during cognitive performance (consequences of Chernobyl accident)]. Zh Vyssh Nerv Deiat Im I P Pavlova, 56, 193-201.

Zubovsky, G.A., \& Kholodova, N.B. (1993). Neurological status of subjects who participated in liquidation of the Chernobyl power plant accident consequences. Journal of Med. Radiology, 38, 31-34.

Received November 21, 2007 Revision received June 25, 2008 Accepted June 27, 2008 